\title{
Study of Profile, Pattern and Outcome of Oral Poisoning Cases admitted in Emergency Department of a Tertiary Care Teaching Hospital in North India
}

\author{
Susan Jalali, M.B.A., ' Shahnawaz Hamid, M.D., ${ }^{2}$ Farooq A Jan, M.D., ${ }^{3}$ Illahay Jalali ${ }^{4}$ \\ 'Medical Officer, ${ }^{2}$ Senior Resident, ${ }^{3}$ Professor, Department of Hospital Administration SKIMS \\ ${ }^{4}$ Medical Student
}

\section{A B S T R A C T}

Introduction: Poisoning is a common medico-social problem. It is a significant contributor to morbidity and mortality. Knowledge of the epidemiology of poisoning and its changes is important to both emergency physicians and public health practitioners. Our study was to determine the socio- demographic profile, pattern and outcome of the poisoning cases reported to Emergency Department of a tertiary care hospital.

Methods: The study was a Retrospective observational type of study conducted at Sheri-Kashmir institute of medical sciences, Srinagar J\&K. The patients with acute poisonings presenting to and managed in the Emergency Medicine department between February 2016 to February 2018 were reviewed for inclusion. Data was collected by reviewing records. Using a pre-structured format, case records of poisoning cases were reviewed for gender, age, residence, type of poison, route of poison and outcome of treatment. The collected data was analysed using descriptive statistical analysis.

Results: In the present study the Female: male ratio was 1.9:1 (131 Females and 68 Males).Females outnumbered the males. Highest cases of Poisoning were reported in age group of 10-20 years. The poisoning in extreme of ages was less observed. Maximum cases of Poisoning belong to rural areas $(60.8 \%)$. The most common implicating agents were Pesticides $(75.3 \%)$. The second common cause of poisoning was drug overdose (20.52\%) Maximum cases recovered after treatment (94\%).

Conclusion: Pattern and magnitude of poisoning are multidimensional and demand multi-sectorial approach for facing this problem. There is need for stringent pesticide regulation laws and counselling and training programs to reduce incidence of poisonings. JMS 2018; 21 (1):24-30 Keywords: Poisoning, pattern, organophosphorus

\section{INTRODUCTION}

Poisoning is a public health problem worldwide $\mathrm{e}^{[1,2,3,4,5,6,2,8,9]}$ and is one of the most common reasons for attendance at hospital emergency departments (EDs) ${ }^{[0,10,11,12]}$. Although the incidence of poisoning is difficult to estimate accurately, the wide availability and accessibility of chemicals and their extensive use in a variety of applications including medicine, agriculture and industry has increased the risk of poisoning ${ }^{[1,2,13] .}$ World Health Organization (WHO) report for the year 2012 states that globally unintentional poisonings have resulted in deaths of 1, 93,460 people and nearly millions die each year as a result of suicide. The stats also suggest that $84 \%$ of these deaths have been recorded

\section{Correspondence}

Dr. Susan Jalali, M.B.A (Hospital Administration)

Medical Officer, Department of Hospital

Administration SKIMS

Email: syedsusanara@gmail.com from low and middle-income countries. ${ }^{(14)}$ According to the report of National Crime Records Bureau (NCRB), under Ministry of Home Affairs, 3, 16,828 un-natural deaths occurred in India in the year 2014 in which poisoning was second most common cause contributing to $17.9 \%$ of all unnatural deaths. ${ }^{(15)}$

The nature of poisoning varies from country and region depending upon socio-economic factors and diversity in the culture. As the majority of Indian population is an agriculture-dependent residing in rural areas, thus easy availability of pesticides have contributed as a major culprit for accidental as well as intentional poisoning and as a result deliberate self-harm has become a major public health problem ${ }^{[16] .}$ Every year 500,000 deaths occur in Asia due to self-harm. It is evaluated that 200,000 of these deaths are due to OP poisoning ${ }^{[17]}$. The easy availability of pesticides through unregulated, open local markets and lack of 
knowledge on the proper storing techniques and use of these lethal compounds contribute to the increasing number of self-harm due to pesticides ${ }^{[18] .}$ Apart from OP compounds, there are other lethal compounds such as aluminum phosphide and pyrethroids, which are also used in poisoning. Drug overdose is the second most common mode of deliberate self-harm after poisoning with pesticides especially OP compounds ${ }^{[19]}$. Both poisoning and drug overdose are associated with a high case-fatality rate. In developing countries, this has been found to be 15 times higher than in developed countries ${ }^{[20]}$.

Knowledge of the epidemiology of poisoning is important to both emergency physicians and public health practitioners, but the treatment of poisoning can vary rapidly (21). Hence, regional epidemiological data on poisoning are very helpful in planning rational use of resources for the prevention and management of poisoning and in targeting research. The current study was conducted in Sheri-Kashmir Institute of Medical Sciences (SKIMS), a 794 bedded teaching hospital located in J\&K state in North India with an aim to determine the socio-demographic details, pattern, and outcomes of poisoning cases.

\section{METHODS}

The study was a Retrospective observational type of study conducted at SKIMS. The patients with acute poisonings presenting to and managed in the Emergency Medicine department between February 2016 to February 2018 were reviewed for inclusion. Data was collected by reviewing records from medico legal cell of the hospital and only those poisoning cases were included wherein Diagnostic confirmation of Gastric lavage was received from Forensic Science Lab. Using a pre-structured format, case records of poisoning cases were reviewed for gender, age, residence, type of poison, route of poison and outcome of treatment. Alcoholics were excluded from the study. Statistical Analysis was carried out following data entry. Categorical data of the determinants were analysed using the chi square test.

\section{RESULTS}

A total of 199 patients were admitted in the department of Emergency Medicine of Sheri-kashmir institute of medical sciences (SKIMS) from February 2016 to February 2018. The socio-demographic profile was categorised according to data available into Gender, age and residence. The Gender distribution of poisoning cases (Fig 1) shows that
$131(65.8 \%)$ cases were females and $68(34.2 \%)$ were males. The female male ratio was found to be 1.9:1. The age groups were studied ( Fig 2) which shows that majority of patients were in the age group of $10-20$ years ( 92 ) i.e $46.2 \%$, followed by $20-30$ years ( 56 ) i.e $28.1 \%$ and then the results showed a progressive fall as the age touched the Geriatric age group which showed least vulnerability to poisoning. The poisoning was predominant among the residents of rural areas (Fig 3) contributing for 121 (60.8\%) patients followed by 78 (39.2\%) patients from urban areas.

Pesticides $(150,75.3 \%)$ were the most common agents implicated in poisonings followed by medicines (41, 20.6\%). (Fig 4a) shows that Organophosphates (142, $71.3 \%$ ) were the most commonly used pesticides in the poisonings followed by Aluminium phosphide $(08,4.02 \%)$ while (Fig 4b) shows that among medications the most implicated class of drugs were sedatives/hypnotics (31, $15.5 \%)$ followed by non- steroidal anti- inflammatory drugs $(6,3.01 \%)$, anti- depressants $(4,2.01 \%)$. The most common sedative/hypnotics used were alprazolam followed by clonazepam while paracetamol was common antiinflammatory implicated in poisoning. Use of Rodenticides (e.g Zinc Phosphide) contributed to $4.02 \%$ of poisonings due to household products.

Out of 199 poisoning cases, $94.0 \%$ were improved and discharged. 8 poisoning cases expired which constitutes about $4.0 \%$ of total cases (Fig 5) while 4 cases $(2.0 \%)$ were lost to follow up as they left against medical advice. The total mortality was found to be $4.06 \%$ and all the mortality cases were due to the ingestion of organophosphorous compounds. The overall mortality with organo phosphorous compound was found to be $5.33 \%$ in present study. The statistical significance derived is shown in Table 1 and Table 2

Out of 8 Expired patients Six (6) patients were from the rural background. The three deaths occurred in the age group of 50-60 years followed by two deaths each in 10-20 and 30-40 years of age group.

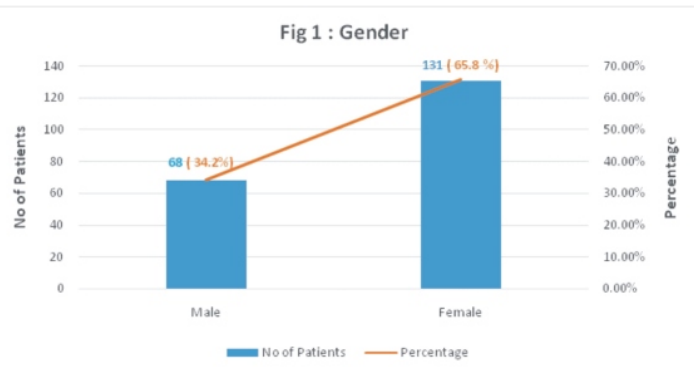




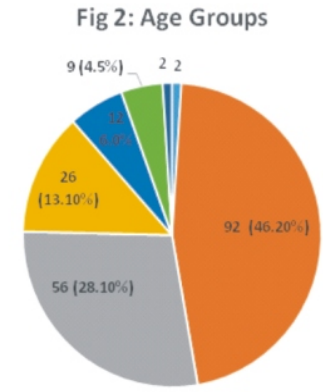

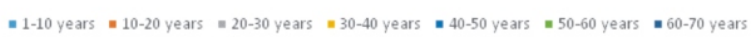

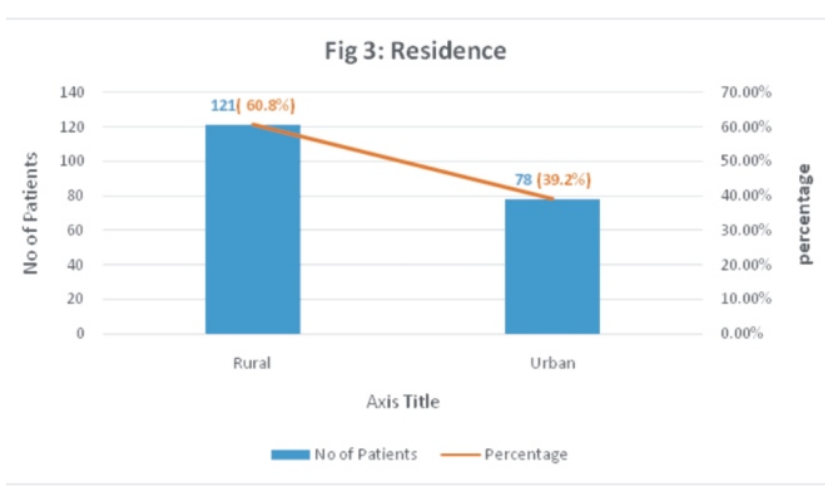

Fig 4a: Type of Poison
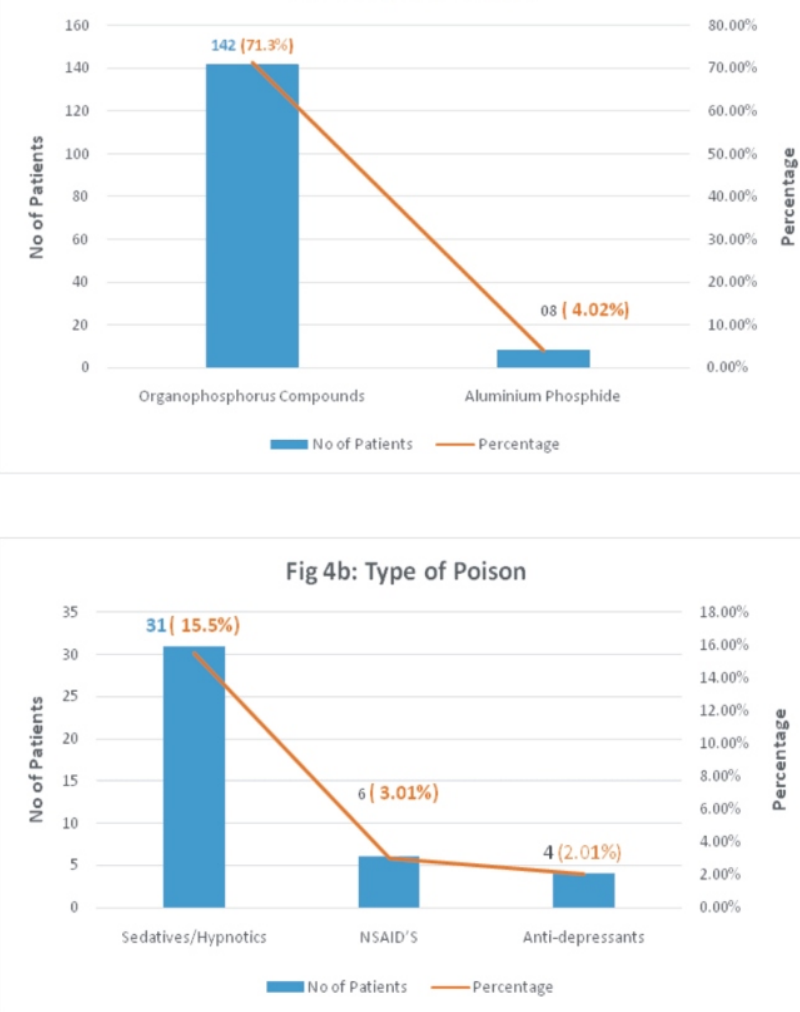

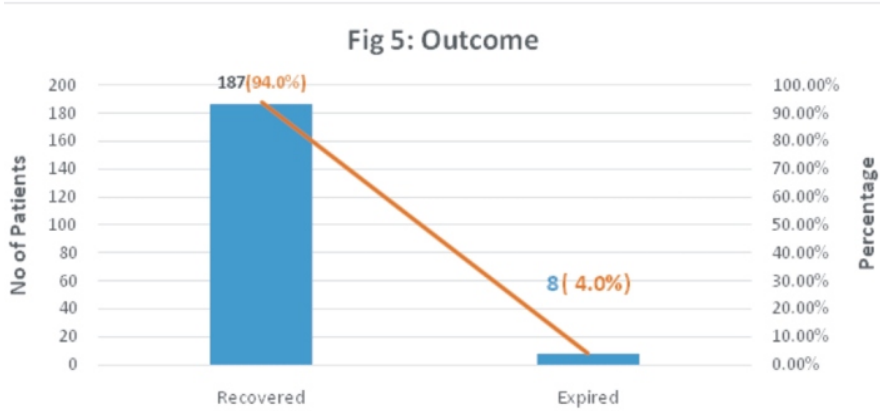

No of Patients Percentage

\begin{tabular}{|c|c|c|c|}
\hline Gender & $\begin{array}{c}\text { No of } \\
\text { Patients }\end{array}$ & Percentage & P value \\
\hline Male & 68 & $34.2 \%$ & 0.80 \\
\hline Female & 131 & $65.8 \%$ & \\
\hline Age Groups & $\begin{array}{c}\text { No of } \\
\text { Patients }\end{array}$ & Percentage & \\
\hline $1-10$ years & 02 & $1.0 \%$ & \\
\hline $10-20$ years & 92 & $46.2 \%$ & \\
\hline $20-30$ years & 56 & $28.1 \%$ & 0.87 \\
\hline $30-40$ years & 26 & $13.1 \%$ & \\
\hline $40-50$ years & 12 & $6.0 \%$ & \\
\hline $50-60$ years & 09 & $4.5 \%$ & \\
\hline $60-70$ years & 02 & $1.0 \%$ & \\
\hline $\begin{array}{c}\text { Area of } \\
\text { Residence }\end{array}$ & $\begin{array}{c}\text { No of } \\
\text { Patients }\end{array}$ & Percentage & \\
\hline Rural & 121 & $60.8 \%$ & $<0.0001$ \\
\hline Urban & 78 & $39.2 \%$ & \\
\hline
\end{tabular}

\begin{tabular}{|c|c|c|c|}
\hline Table 2: Type of Poison & \multicolumn{1}{l|}{} \\
\hline Pesticides/Insecticides & $\begin{array}{c}\text { No of } \\
\text { Patients }\end{array}$ & Percentage & P- Value \\
\hline $\begin{array}{c}\text { Organophosphorus } \\
\text { Compounds }\end{array}$ & 142 & $71.3 \%$ & $<0.0001$ \\
\hline Aluminium Phosphide & 08 & $4.02 \%$ & \\
\hline Medicines & $\begin{array}{c}\text { No of } \\
\text { Patients }\end{array}$ & Percentage & \\
\hline Sedatives/Hypnotics & 31 & $15.5 \%$ & \\
\hline NSAID'S & 06 & $3.01 \%$ & $<0.0001$ \\
\hline Anti-depressants & 04 & $2.01 \%$ & \\
\hline Household Products & $\begin{array}{c}\text { No of } \\
\text { Patients }\end{array}$ & Percentage & \\
\hline Rodenticides & 08 & $4.02 \%$ & \\
\hline
\end{tabular}

\section{DISCUSSION}

Poisoning is a common medico-social problem all over the world. It consumes not only the valuable health service resources but also causes considerable morbidity and mortality Many factors affect the outcome including the degree to which the poison's toxicity is understood, the speed at which patient comes to clinical attention and the availability of effective medical treatment. 
The present study has reported female to male ratio of 1.9:1. Various studies have reported very high female preponderance. In a study reported by Bajracharya et al, almost three fourth of the cases were females. ${ }^{[22]}$ A study by Paudyal BP also found female preponderance with $59.5 \%$ of cases being females and $40.5 \%$ males ${ }^{[23]}$ while hakim et al revealed in 2014 that incidence of female cases was $73.07 \%$ (24) In the same aspect, our study showed female preponderance of poisoning cases $(65.8 \%$ were females while $34.2 \%$ were males). Ghimere et al, in their comparison of data of poisoning also noticed significant increase in percentage of male poisoning cases from $31.4 \%$ to $42.7 \%$. ${ }^{[25]}$

Studies from Iran (Asia), Ethiopia (Africa) and Tanzania (Africa) reflected that incidence of poisoning was high amongst males whereas in a study conducted in south-east Melbourne (Australia) the females outnumbered the males showing similar results as our study. Among the European population a one year retrospective study conducted at Queen Medical Centre, Nottinghamshire (Europe) observed contrary results to our study showing that intentional poisoning was more common in males when compared to female population while similar results to our study were observed in two year retrospective analysis conducted in Scotland (Europe) and Wales (Europe). ${ }^{[2-32]}$

Majority of the cases in our study were from the age group of 10-20 years followed by 21-30 years among both male and female population. The reason behind this can be the fact that the person from this age group suffers from more stress. The stress factors may be financial, marital, professional, family problems, impulsive behavior etc. The majority of the studies from India have shown that 15-30 years of age group is mostly victimized by poisoning ${ }^{[3-36]}$ there was a similar pattern observed in the studies of Iran, Ethiopia, Tanzania and Australia, reflecting that the age group from 15-30 years is most affected age group in other countries apart from India, reflecting the need to target this population group to detect the stress factors at earliest and to provide proper counseling. ${ }^{[26-28]}$ Moreover, from the studies conducted in Europe it was observed as intentional poisonings were more common in age group of 15-19 years followed by $20-24$ years. ${ }^{[30-32]}$

In developing countries like Ethiopia and Tanzania, the majorities of the poisoning victims were from the urban background and for livelihood were dependent on professional jobs like Nurse, Lawyer and accountant and the similar pattern was observed among the studies from Australia and Europe. ${ }^{(26-32)}$ Contrarily in our study we found that most of the poisoning victims were residents of rural areas and a majority of them were dependent on the agriculture for livelihood thus this can explain the use of pesticides in poisonings because of easy access, which was analogous to other studies conducted in India. ${ }^{[33]}$ Moreover economic problems, failure of crops and family problems are also contributing factor for poisoning in people with aforementioned background.

The reason for the poisoning varies from regions and countries. In our study, the motive of the poisoning was found to be intentional in the majority of the poisoning victims. The pesticides were the most common implicated agents in deliberate poisonings in our study as access to pesticides is quite easy and at a low cost among the rural population from the agrarian background. Among the pesticides organophosphates were the most implicated pesticides followed by Aluminum phosphide. The similar pattern of poisoning was seen in most of the Indian studies. ${ }^{(37,38)}$ In contrast, studies from Iran, Tanzania, Australia and United Kingdom revealed that medicines like Benzodiazepines, Paracetamol, Analgesics and Antidepressants were most implicated agents in deliberate poisoning whereas poisonings with pesticides were rare and were mostly associated with accidental exposure to pesticides. However the studies conducted in Ethiopia, Brazil, Caribbean and Ecuador revealed similar results as our study showing that pesticides were the most implicated agents in poisoning. ${ }^{[26-32]}$

Out of 199 patients included in our study, 187 (94.00\%) improved while 08 patients $(4.02 \%)$ expired. A total of 04 $(2.0 \%)$ patients lost to follow up because they were discharged against the medical advice. The main cause of death was organophosphate poisoning. Other studies also show that organophosphate pesticides were responsible for the maximum number of deaths among poisoning cases. In contrast to our study, some studies show that the poison responsible for most of the mortality was aluminum phosphide. $^{[3,373]}$

\section{CONCLUSION}

Our study showed that female poisoning cases are increasing and younger age group is more vulnerable for poisoning. Pesticide consumption remains the commonest 
agent used for poisoning followed by drug overdose. Establishment of strict policies against the sale and availability of agricultural field products and over the counter drugs are an effective way to control OP and drug poisoning. The public awareness campaign should be conducted in the rural and semi-urban areas about the seriousness of problem through health education and educating them on the first aid measures in poisoning cases. Personnel guidance or counselling to students, unemployers, agricultural farmers and house wives from public/private medical professionals may decrease the incidence. Training of physicians in the accurate diagnosis and prompt management of poisoned victims would improve the rate of survival. A widespread campaign to inform people of the possible dangers of poison would be useful.

\section{REFERENCES}

1. Watson WA, Litovitz TL, Rodgers GC, KleinSchwartz W, Reid N, Youniss J, Flanagan A, Wruk KM: 2004 Annual report of the American Association of Poison Control Centers Toxic Exposure Surveillance System. Am J Emerg Med. 2005, 23: 589666. $10.1016 / \mathrm{j} \mathrm{ajem.2005.05.001.} \mathrm{View}$ ArticlePubMedGoogle Scholar

2. Yang CC, Wu JF, Ong HC, Hung SC, Kuo YP, Sa CH, Chen SS, Deng JF: Taiwan National Poison Center: epidemiologic data 1985-1993. J Toxicol Clin Toxicol. 1996, 34: 651-663. View ArticlePubMedGoogle $\underline{\text { Scholar }}$

3. Akkose S, Bulut M, Armagan E, Cebicci H, Fedakar R: Acute poisoning in adults in the years 1996-2001 treated in the Uludag University Hospital, Marmara Region, Turkey. Clin Toxicol (Phila). 2005, 43: 105109. Google Scholar

4. Lapatto-Reiniluoto O, Kivisto KT, Pohjola-Sintonen S, Luomanmaki K, Neuvonen PJ: A prospective study of acute poisonings in Finnish hospital patients. Hum Exp Toxicol. 1998, 17: 307-311. $10.1191 / 096032798678908864$. View ArticlePubMedGoogle Scholar

5. Hanssens Y, Deleu D, Taqi A: Etiologic and demographic characteristics of poisoning: a prospective hospital-based study in Oman. J Toxicol Clin Toxicol. 2001, 39: 371-380. 10.1081/CLT100105158.View ArticlePubMedGoogle Scholar
6. Burillo-Putze G, Munne P, Duenas A, Pinillos MA, Naveiro JM, Cobo J, Alonso J: National multicentre study of acute intoxication in emergency departments of Spain. Eur J Emerg Med. 2003, 10: 101-104. 10.1097/00063110-200306000-00006. View ArticlePubMedGoogle Scholar

7. Bruyndonckx RB, Meulemans AI, Sabbe MB, Kumar AA, Delooz HH: Fatal intentional poisoning cases admitted to the University Hospitals of Leuven, Belgium from 1993 to 1996. Eur J Emerg Med. 2002, 9: 238-243. 10.1097/00063110-20020900000006.View ArticlePubMedGoogle Scholar

8. Hatzitolios AI, Sion ML, Eleftheriadis NP, Toulis E, Efstratiadis G, Vartzopoulos D, Ziakas AG: Parasuicidal poisoning treated in a Greek medical ward: epidemiology and clinical experience. Hum Exp Toxicol. $2001, \quad 20: 611-617$. $10.1191 / 096032701718890595$. View ArticlePubMedGoogle Scholar

9. Henderson A, Wright M, Pond SM: Experience with 732 acute overdose patients admitted to an intensive care unit over six years. Med J Aust. 1993, 158: 2830.PubMedGoogle Scholar

10. Goksu S, Yildirim C, Kocoglu H, Tutak A, Oner U: Characteristics of acute adult poisoning in Gaziantep, Turkey. J Toxicol Clin Toxicol. 2002, 40: 833-837. $10.1081 / \mathrm{CLT}-120016953$. Vi e w ArticlePubMedGoogle Scholar

11. Lamireau T, Llanas B, Kennedy A, Fayon M, Penouil F, Favarell-Garrigues JC, Demarquez JL: Epidemiology of poisoning in children: a 7-year survey in a paediatric emergency care unit. Eur J Emerg Med. 2002, 9: 9-14. 10.1097/00063110-200203000-00004. View ArticlePubMedGoogle Scholar

12. Tufekci IB, Curgunlu A, Sirin F: Characteristics of acute adult poisoning cases admitted to a university hospital in Istanbul. Hum Exp Toxicol. 2004, 23: 347351.10.1191/0960327104ht460oa.View ArticlePubMedGoogle Scholar

13. Fernando R: The National Poisons Information Centre in Sri Lanka: the first ten years. J Toxicol Clin Toxicol. 2002，40: 551-555. 10.1081/CLT-120014644.View ArticlePubMedGoogle Scholar

14. World Health Organization. WHO/Poisoning 
Prevention and Management. [homepage on the Internet]. 2012 [cited 2017 Apr 16]. Available from: World Health Organiation, International Programme on Chemical Safety

15. National Crime Records Bureau. adsi-2014 full report. [homepage on the Internet]. 2014 [cited 2017 Apr 16]. Available from: National Crime Records Bureau, Accidental Deaths and Suicides in India (ADSI)

16. Chowdhary AN, Banerjee S, Brahma A, Biswas MK. Pesticide poisoning in nonfatal, deliberate self-harm: A public health issue: Study from Sundarban Delta, India. Indian J Psychiatry 2007;49(4):117-20.

17. Eddleston M, Buckley NA, Eyer P, Dawson AH. Management of acute organophosphorus pesticide poisoning. Lancet 2008;371(9612):597-607.

18. Chowdary AN, Sanyal D, Dutta SK, Weiss MG. Deliberate self-harm by ingestion of poisons on Sagar Island in Sundarban Delta, India. Int Med J 2003;10:85-91.

19. Vijaykumar L. Suicide and its prevention: The urgent need in India. Indian J Psychiatry 2007;49(2):81-4.

20. Eddleston M, Gunnell D, Karunaratne A, de Silva D, Sheriff MH, Buckley NA Epidemiology of intentional self-poisoning in rural Sri Lanka. Br J Psychiatry 2005;187:583-4

21. 21. Hsin-Ling Lee,et al, Presentations of patients of poisoning and predictors of poisoning-related fatality: Findings from a hospital-based prospective study; BMC Public Health20088:7; https://doi.org/ 10.1186/1471-2458-8-7

22. Bajracharya MR, Manandhar K, Deo KK, et al. Age and gender distribution in deliberate self poisoning Cases. Pmjn 2008; 8:44-9.

23. Paudyal BP. Poisoning: pattern and profile of admittedcases in hospital in central Nepal. J Nep Med Assoc 2005; 44:92-6.

24. Hakim et al; Pattern, profile and outcome of poisoning cases: a study at a large teaching hospital in north India; JK-Practitioner 2014;19(1-2):36-40

25. Ghimere RH, Pathak UN, Sharma SP, et al. Retrospective study of poisoning cases admitted in Nepal Medical College Teaching Hospital. Nep Med Col J 2001;3:101-5.26

26. M. Shokrzadeh, A. Hajimohammadi, R. Hoseinpoor,
A. Delaram, Y. Shayeste, An epidemiological survey of drug poisoning and a comparison with other poisonings cases admitted to a university hospital in, Int. J. Epidemiol. Res. 4 (2017) 94103.

27. G.M. Adinew, A.B. Asrie, E.M. Birru, Pattern of acute organophosphorus poisoning at University of Gondar Teaching Hospital, Northwest Ethiopia, BMC Res. Notes. 10 (2017) 16. doi:10.1186/s13104-017-2464-5.

28. G.S. Mbarouk, H.R. Sawe, J.A. Mfinanga, J. Stein, S. Levin, V. Mwafongo, M.S. Runyon, T.A. Reynolds, K.R. Olson, Patients with acute poisoning presenting to an urban emergency department of a tertiary hospital in Tanzania, BMC Res. Notes. 10 (2017) 17.doi:10.1186/s13104-017-2807-2.

29. A. Rahman, C. Martin, A. Graudins, R. Chapman, Deliberate self-poisoning presenting to an emergency medicine network in South-East Melbourne: A descriptive study, Emerg. Med. Int. (2014) 17. doi:10.1155/2014/461841.

30. K. Prescott, R. Stratton, A. Freyer, I. Hall, I. Le Jeune, Detailed analyses of self-poisoning episodes presenting to a large regional teaching hospital in the UK, Br. J. Clin. Pharmacol. 68 (2009) 260268. doi:10.1111/j.1365-2125.2009.03458.x.

31. M.W. Doak, A.C. Nixon, D.J. Lupton, W.S. Waring, Self-poisoning in older adults: Patterns of drug ingestion and clinical outcomes, Age Ageing. 38 (2009) 407411. doi:10.1093/ageing/afp046

32. M. Bialas, P. Reid, P. Beckjh Lazarus, P. Smith, R. Scorer, P. Routledge, Changing patterns of selfpoisoning in a UK health district, Q J Med. 89 (1996) 893901.

33. Ali, K. Sawlani, H. Dandu, S. Chand Chaudhary, K. Usman, V. Atam, P. Khan Mohd, study of pattern and outcome of acute poisoning cases at tertiary care hospital in North India, J. Evid. Based Med. Healthc. 4 (2017) 326-331. doi:10.18410/jebmh/2017/62 .

34. N. Mittal, N. Shafiq, A. Bhalla, P. Pandhi, M. Samir, A prospective observational study on different poisoning cases and their outcomes in a tertiary care hospital, S A G E O pe n M e d . O $\left.\quad \begin{array}{llllll}2 & 0 & 1 & 3\end{array}\right) \quad 15$. doi:10.1177/2050312113504213.

35. N. Kiran, R.H. Shobha Rani, V. JaiPrakash, K. Vanaja, Pattern of poisoning reported at south Indian tertiary 
care hospital, Indian J. Forensic Med. Toxicol. 2 (2008) 17-19. 21. B. Maharani, N. Vijayakumari, Profile of poisoning cases in a Tertiary care Hospital, Tamil Nadu, J. Appl. Pharm. Sci. 3 (2013) 9194. doi:10.7324/JAPS.2013.30117.

36. K Raghu, p. Shreevani, S.S. Kumar, S. Gopal, M.V. Shaik, B. Ahammed, Incidence and outcome of poisoning patients in a tertiary care teaching hospital, Asian J. Pharmacol. Toxicol. 3 (2015) 2326.
37. B. Singh, B. Unnikrishnan, A profile of acute poisoning at Mangalore (South India), J. Clin. Forensic Med. 13 (2006) 112116. doi:10.1016/j.jcfm.2005.09.005 